\title{
Fluorescein Isothiocyanate-Dextran can Track Apoptosis and Necrosis Induced by Heat Shock of Peripheral Blood Mononuclear Cells and HeLa Cells
}

\author{
Mohamed Moumaris $^{\mathrm{a}, \mathrm{b}, \mathrm{c}}$, Bakoliarisoa Rajoely ${ }^{\mathrm{a}, \mathrm{b}, \mathrm{c}}$ and Nisen Abuaf $\mathrm{f}^{\mathrm{a}, \mathrm{b}, \mathrm{c}, *}$ \\ ${ }^{a}$ Hôpital Rothschild AP-HP, 5 Rue Santesse, 75012 Paris, France \\ ${ }^{b}$ Hopital Tenon, AP-HP 4 Rue de la Chine, 75020 Paris, France \\ ${ }^{c}$ Université Pierre et Marie-Curie, 4 Place Jussieu, 75005 Paris, France
}

\begin{abstract}
Dextran does not penetrate the living cells. However when the plasma membrane becomes permeable, it is concentrated in the cells. This is why we used fluorescein isothiocyanate-conjugated dextran (FITC-Dextran, MW 4000) to identify apoptotic and necrotic cells by flow cytometry. Heat shock was used to induce cell apoptosis or necrosis. To induce apoptosis cells were heated to $43.5^{\circ} \mathrm{C}$ for 1 hour and then incubated at $37^{\circ} \mathrm{C}$. Thereafter the cells were stained with FITC-Dextran or propidium iodide (PI), and analyzed by flow cytometry. FITC-Dextran stained the cytoplasm and/or the nucleus of $80 \%$ of the HeLa cells, while annexin V-FITC stained $43 \%$ of cells and PI stained the nucleus of $18 \%$ of cells. When heated at $50^{\circ} \mathrm{C}$ and $60^{\circ} \mathrm{C}$, the percentages of necrotic cells increased proportionally to heat treatment, $41.7 \%$ and $77 \%$ of the cells were stained by FITC-Dextran, while $39.5 \%$ and $70.3 \%$ were stained by PI. FITC-Dextran was selectively internalized across plasma membrane after moderate heat shock. In contrast, in the necrotic cells, the permeability of the membrane was not selective and the percentage of cells stained with FITC-Dextran or PI, was equivalent. Our results indicate that FITC-Dextran can be used as a marker to reveal the cellular damage induced by heat shock and to study the early as well as the late stages of apoptosis.
\end{abstract}

Keywords: Apoptosis, flow cytometry, fluorescein labeled dextran, heat shock, lethal hyperthermia, necrosis, propidium iodide.

\section{INTRODUCTION}

Necrosis "passive death" is caused by cell injury induced by stress. It generates the alteration of the permeability of the plasma membrane resulting in the release of cytoplasmic components of the cell, which triggers the inflammatory process. In contrast, apoptosis "active death" is programmed to remove unwanted cells, such as cancer cells or infected cells $[1,2]$. Apoptosis involves the activation of specific genes and is accompanied by an active nuclear fragmentation by endonucleases. It is characterized by cytoplasmic granularity, cell shrinkage and puffiness of the plasma membrane causing apoptotic bodies [3, 4].

Flow cytometry is widely used in detecting apoptotic cells [5]. Apoptosis can be detected by various molecular probes, however each probe identifies apoptosis in the early stages or at an advanced stage, but not both. To follow all the steps, it is necessary to combine several markers [6, 7]. The translocation of phosphatidylserine from the inner leaflet of the plasma membrane to the outer layer, is an early event of

\footnotetext{
*Address correspondence to this author at the Service d'Hématologie et d'Immunologie Biologique or Service de Dermatologie et d'Allergie, Hôpital Tenon, 4 rue de la Chine, 75970 PARIS Cedex 20, France; Tel: 0033156017343; Fax: 0033156017780;

E-mail: nissen.abuaf@tnn.aphp.fr
}

apoptosis. It can be detected by the binding of a protein with high avidity for phosphatidylserine, annexin $\mathrm{V}$, to the plasma membrane [8]. In spite of this early event, the integrity of the plasma membrane is preserved and most functions of the membrane remain unchanged. Apoptotic cells in the early stages exclude viability testing dyes such as trypan blue or propidium iodide (PI), a DNA binding dye, while late stage apoptotic or necrotic cells take up PI which stains the nucleus [9]. Plasma membrane integrity seems to contrast with mitochondrial membrane depolarization, alteration of membrane permeability and the release of proteins such as cytochrome c, which are early apoptotic events of the intrinsic pathway [10].

To work on apoptosis and necrosis we used peripheral blood mononuclear cells and HeLa cells. The latter is an immortal cell line derived from cervical cancer, which is easily cultured in vitro, multiply quickly and have excellent cell viability $[9,11,12]$. We stained with FITC-Dextran and PI, heat shock stressed cells. After a mild heat shock to induce apoptosis, FITC-Dextran was selectively internalized through the plasma membrane though PI was excluded in a majority of the cells. However in necrotic cells, membrane permeability was not selective and the percentage of cells stained by FITC-Dextran or PI was equivalent. Our findings 
show that FITC-Dextran can be used as a label to analyse cell damage induced by heat shock and to examine the early as well as the late phases of apoptosis.

\section{MATERIALS AND METHODS}

\subsection{Cells Preparation for Apoptosis}

To induce apoptosis we worked with HeLa cells (lined cells), very commonly used in laboratories (a kind gift from Professor Jean-Claude Nicolas, Virology Laboratory, Hospital Rothschild and Hospital Tenon, AP-HP). HeLa cells were maintained in RPMI medium (Gibco, Cergy Pontoise, France) containing 10\% heat-inactivated fetal bovine serum, $2 \mathrm{mM}$ glutamate, $100 \mathrm{U} / \mathrm{ml}$ penicillin, and 0.1 $\mathrm{mg} / \mathrm{ml}$ streptomycin. HeLa cells at a concentration of $5.10^{5}$ cells $/ \mathrm{ml}$ set in culture dishes, are incubated at $37^{\circ} \mathrm{C}$ for 48 hours in 5\% CO2 and 95\% air; check HeLa cells to less than $2 \%$ cell death was made by blue trypan. Cells resist and do not fit easily into apoptosis in culture, competence apoptotic cell lines vary in resistance $(<3 \%)$ to hypersensitivity (> 96\%); to induce apoptosis HeLa cells are incubated in a water bath for 1 hour at $43.5^{\circ} \mathrm{C}$, then for about 8 hours at $37^{\circ} \mathrm{C}$ in $5 \% \mathrm{CO} 2$ and $95 \%$ air; control HeLa cells were incubated for 9 hours at $37^{\circ} \mathrm{C}$ in $5 \% \mathrm{CO} 2$ and $95 \%$ air.

\subsection{Cells Preparation for Necrosis}

Peripheral blood mononuclear cells (PBMC) donors were healthy subjects $(n=16)$; those are quiescent cells in G0 phase. The study protocol was in accordance with the local ethical committee guidelines. Peripheral blood mononuclear cells were isolated from EDTA anti-coagulated blood (Vacutainer $7 \mathrm{ml}$ plastic tubes, Beckton Dickinson, Le Pont de Claix, France) by centrifugation at 500g for 20 minutes at $20^{\circ} \mathrm{C}$ on a layer of Ficoll $(\mathrm{d}=1.077)$ (Eurobio, Les Ulis, France), then washed with RPMI medium; check cells to less than $2 \%$ cell death was made by blue trypan. To induce necrosis, peripheral blood mononuclear cells or HeLa cells at a concentration of $5.10^{5}$ cells $/ \mathrm{ml}$, were suspended in the culture medium RPMI, and then incubated in a water bath for about 1 hour at $50^{\circ} \mathrm{C}$ or $60^{\circ} \mathrm{C}$; control cells were incubated for 1 hour at room temperature.

\subsection{Labeling of Cells}

Treated HeLa cells, control HeLa cells, treated PBMC and control PBMC were washed with $3 \mathrm{ml}$ of RPMI medium and centrifuged for 10 minutes at $500 \mathrm{~g}$. The cells were resuspended in $100 \mu$ l of RPMI medium and mixed in Q-prep tubes with $10 \mu \mathrm{l}$ of PI (Sigma, Saint-Quentin Fallavier, France), $10 \mu \mathrm{l}$ of FITC-Dextran (MW 4000 daltons, reference 46944), or $5 \mu \mathrm{l}$ of Annexin V-FITC (SigmaAldrich reference A9210). The final concentration of PI and FITC-dextran was $7.5 \mu \mathrm{M}$ and $1.13 \mu \mathrm{M}$, respectively. The cells were then incubated for 25 minutes at room temperature in the dark. The labeled cells are taken with $3 \mathrm{ml}$ of RPMI medium and centrifuged for 10 minutes at $500 \mathrm{~g}$. The cells are then taken with $1 \mathrm{ml}$ of RPMI medium and analyzed by flow cytometry or fluorescence microscopy.

\subsection{Microscopy and Photography}

Immunofluorescence and cell images were acquired on Zeiss Axioplan microscope equipped with the filter set 09 (Excitation 450-490, Beam splitter FT 510, Emission LP 515), the filter set 15 (Excitation BP 546, Beam Splitter FT 580, Emission LP 590) and the camera MC80DX.

\subsection{Analysis by Flow Cytometry}

The sample was analyzed on COULTER EPICS XL flow cytometry equipped with single argon ion laser $(15 \mathrm{~mW}, 488$ $\mathrm{nm})$. PI is excited at $500 \mathrm{~nm}$ and has an emission at $600 \mathrm{~nm}$; FITC-Dextran is excited at $495 \mathrm{~nm}$ and has an emission at $525 \mathrm{~nm}$. The photomultiplier (PMT) captures the fluorescence passing through the filters; and it generates electrical signals by amplifying and increases tension. Band Pass filters select the photons entering the PMT, avoiding the overlapping emission spectra of the fluorochromes. Compensation subtracts the interference due to leakage of fluorescence captured by sensors in the PMT, according to an equation in which we subtract a percentage of the green fluorescence from FITC-Dextran (FL1) to the orange fluorescence from PI (FL2) "FL2 compensated = FL2 uncompensated - z\% FL1"; this was taken into consideration in our labeling experiments simultaneously with FITC and PI, due to an overlap of emission spectra. Photomultiplier tube voltage and spectral compensation were also set by using cells stained with only a single dye Either FITC or PI.

Fluorescent beads (Flow-CheckTM Beckman Coulter) were used to control the values of fluorescence. For each sample, a region for apoptotic and necrotic cells was defined; lyophilized human lymphocytes (CYTOTROL BeckmanCoulter) were used to control the results. To analyze cells by flow cytometry we used four histograms; a first histogram bi-parametric wherein the cell size (FS log) depending on the cell structure (SS log), cell population stained with PI or FITC-Dextran was gated on the basis their forward and side light scatter with any cell debris excluded from analysis; cells will be analyzed in a second histogram bi-parametric of FS log versus fluorescence markers, the numbers in a parenthesis is the mean percentage of dead cells FITCDextran+ in case C2 or PI+ in case E2; a third histogram biparametric of fluorescence FITC-Dextran versus fluorescence PI, the numbers in a parenthesis is the mean percentage of dead cells FITC-Dextran+ / PI+ in case E2; a fourth histogram mono-parametric, wherein the number of cells is a function of the fluorescence markers, the numbers in a parenthesis is the mean percentage of dead cells FITCDextran+ at cursor I or PI+ at cursor F.

\section{RESULTS}

Living HeLa cells and human PBMC were unstained by PI, annexin V-FITC or FITC-Dextran (Fig. 1 and Table 1). After induction of apoptosis by heating for 1 hour at $43.5^{\circ} \mathrm{C}$ and incubating at $37^{\circ} \mathrm{C}$, the nucleus of some cells was brightly stained by PI and the staining was proportional to DNA content of cells. FITC-Dextran stained cells were distributed among three peaks corresponding to unstained, dim stained and bright stained cells (Fig. 2). In dim stained cells, FITC-Dextran was present only in the cytoplasm; but 

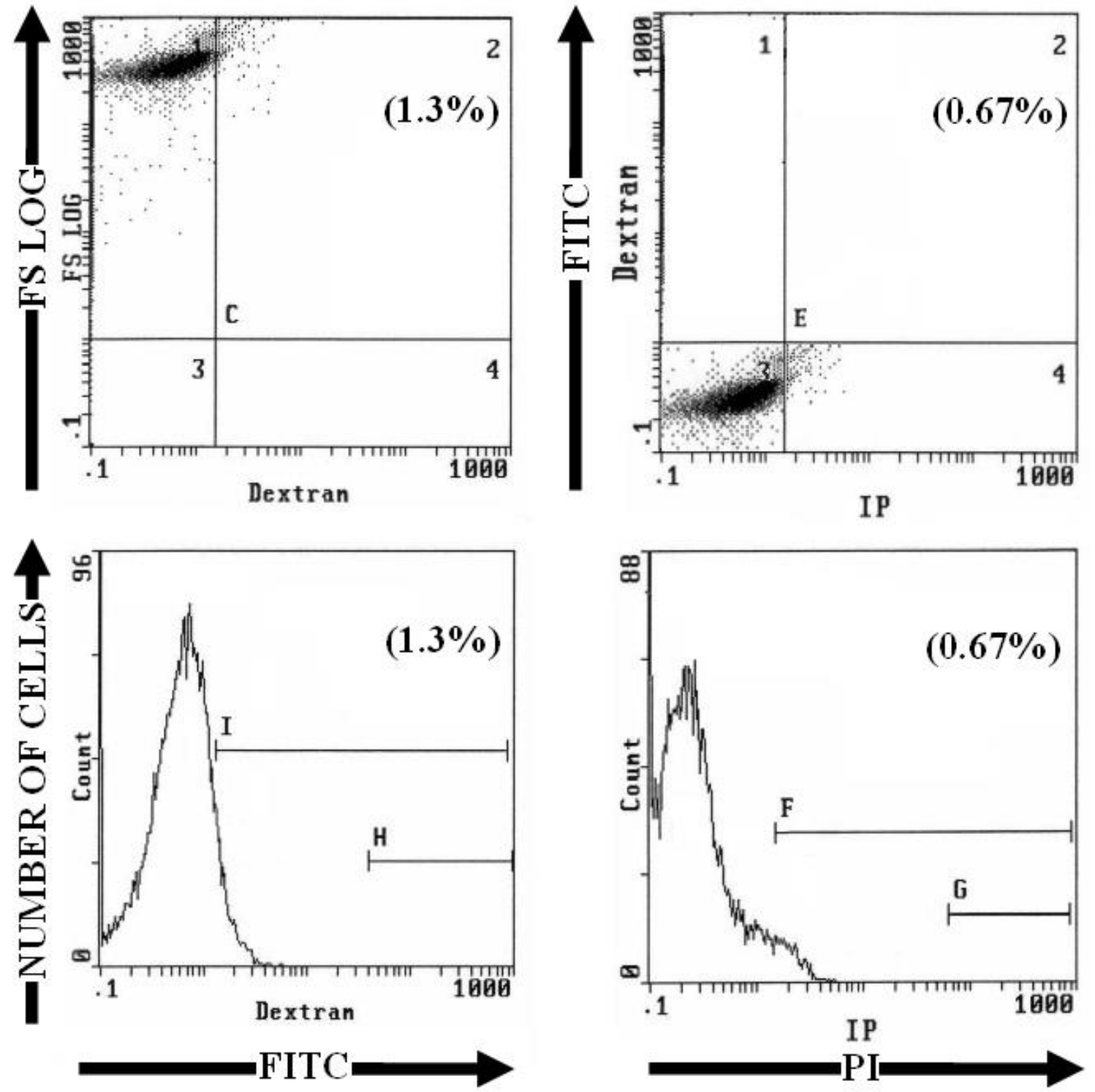

Fig. (1). Analysis by flow cytometry of live HeLa cells incubated with FITC-Dextran or PI. These dyes do not penetrate into living cells. On the histograms the background noise of the fluorescence is visible. The cells were targeted by scatters (FS, SS).

Table 1. Staining with FITC-Dextran, PI or Annexin V-FITC apoptotic cells induced by a heat shock.

\begin{tabular}{|c|c|c|c|c|}
\hline \multirow{2}{*}{ Cells* } & \multicolumn{4}{|c|}{ \% stained cells } \\
\cline { 2 - 5 } & FITC-Dextran & PI & Annexin V & Statistics (Student t test) \\
\hline \hline HeLa control & $1.3 \pm 0.83$ & $0.67 \pm 0.22$ & $1.8 \pm 0.9$ & $\mathrm{p}<0.001$ \\
\hline HeLa heated & $79.6 \pm 5.5 \%$ & $18.2 \pm 1$ & $42,6 \pm 3.8$ & $2 \pm 0.7$ \\
\hline PBMC control & $1.42 \pm 0.86 \%$ & $1.03 \pm 0.32$ & $38.9 \pm 4.5$ & $\mathrm{p}<0.001$ \\
\hline PBMC heated & $70.3 \pm 6.2 \%$ & $15 \pm 1.8 \%$ & \\
\hline
\end{tabular}

*Cells were incubated at $43,5^{\circ} \mathrm{C}$ for 1 hour and at $37^{\circ} \mathrm{C}$ for 8 hours to induce apoptosis; then they were labelled with Annexin V-FITC, FITC-Dextran and PI, then analysed by flow cytometry. Control cells were unheated. The results represent the means \pm S.D of 16 different samples, each tested twice.

in bright stained cells, FITC-Dextran was present in cytoplasm and nucleus (Fig. 3). The fraction of cells stained with FITC-Dextran, was three times more than those stained by PI or by Annexin V-FITC $(\mathrm{p}<0.001)$ (Table 1). This suggests that FITC-Dextran stains different stages of cell damage induced by heat shock, from early stages to late stages of apoptosis with fragmentation of the nucleus and very late stage with loss of nucleus. While PI marks apoptotic cells still having a nucleus even if it is fragmented. 

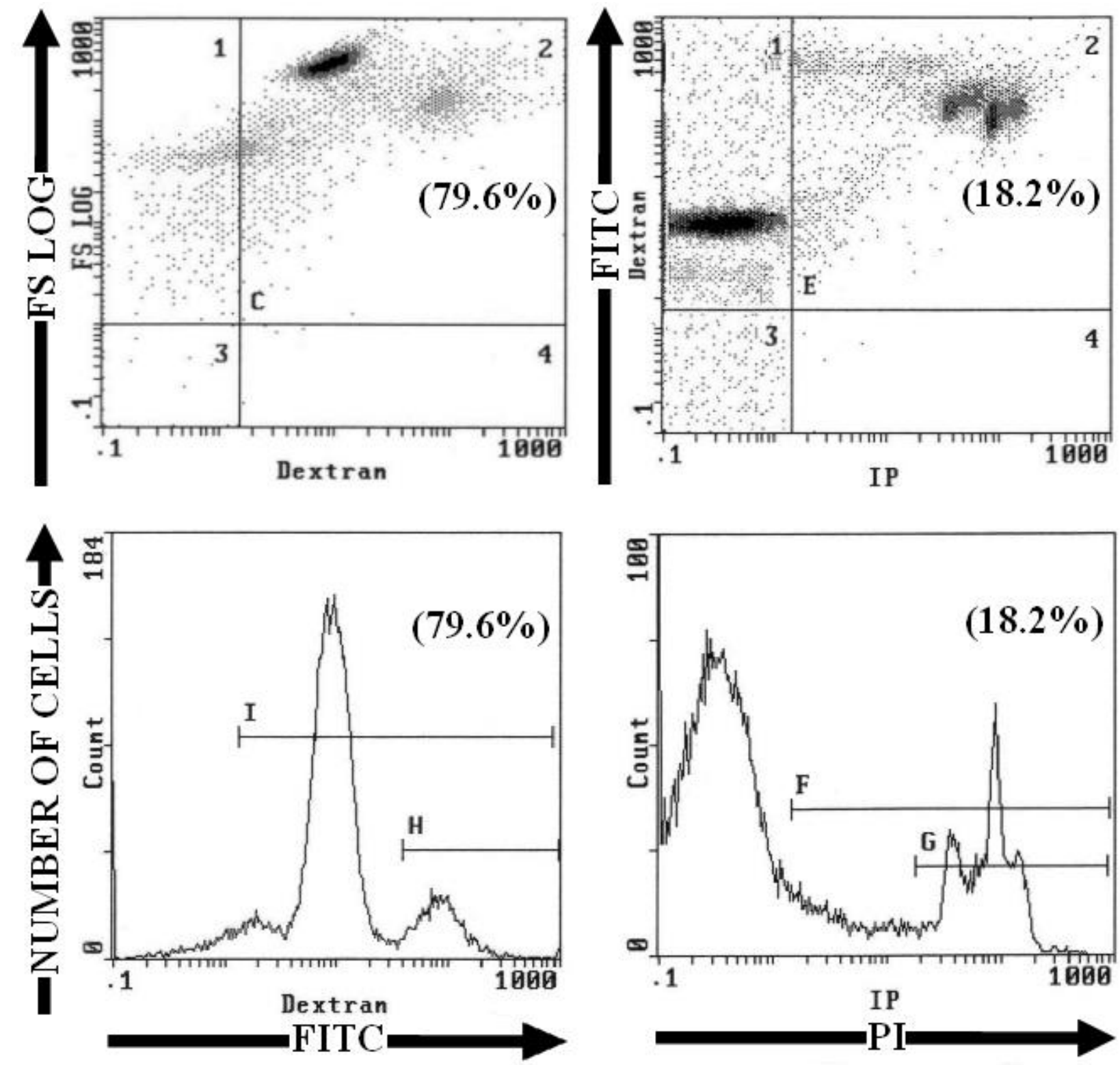

Fig. (2). Analysis by flow cytometry of apoptotic HeLa cells stained with FITC-Dextran and PI. Apoptosis was induced by incubating the cells at $43.5^{\circ} \mathrm{C}$ for 1 hour and at $37^{\circ} \mathrm{C}$ for 8 hours. Then the cells were labeled with PI or FITC-Dextran. The results are typical of those seen with the 16 different samples, each tested twice.

FITC-Dextran stained cells were distributed among three peaks of frequency corresponding to unstained, dim stained and bright stained cells. The population dim stained with FITC-Dextran was unstained by PI, in contrast to the bright stained one which was also stained by PI. Staining by PI was proportional to the DNA content of the cells, so they were distributed among several peaks. Because HeLa cells were actively proliferating cancer cells, when harvested they were at different stages of the cell cycle G1, G2 or S, or were aneuploid, so they contain varying amounts of DNA; some cells had fractioned nucleus and having lost a part of the DNA due to apoptosis; some cell aggregates were also present.

In the left histogram, cursor I underlines the peak of dim stained cells with FITC-Dextran, cursor H underlines the bright stained cells. In the right histogram, the cursor G underlines three peaks of bright PI stained cells (dead cells), cells in G1 of cell cycle, those in G2 and the polyploid or agregated cells. The dim stained cells, at the left of cursor $\mathrm{G}$ and underlined by cursor $\mathrm{F}$, are at the different stages of apoptosis.

To induce cell necrosis HeLa cells and PBMC were heated at $50^{\circ} \mathrm{C}$ or $60^{\circ} \mathrm{C}$ for 1 hour, then incubated with FITC-Dextran and or PI. In single staining, FITC-Dextran and or PI stained roughly the same percentages of cells (the difference was not statistically significant). Double staining confirmed that all dead cells were stained both with FITCDextran and with PI. In cells heated at $50^{\circ} \mathrm{C}$, FITC-Dextran stained cells were distributed over several peaks of fluorescence intensity. Each peak could be related to the intensity of necrosis, the most affected cells are more permeable to staining. In contrast in cells heated at $60^{\circ} \mathrm{C}$, cells were stained brightly by FITC-Dextran in one large peak (Fig. (4) for PBMC); and FITC or PI stained cells were aproximately twice as many than in cells heated at $50^{\circ} \mathrm{C}$ $(\mathrm{p}<0.001 ; \mathrm{n}=16)$ (Table 2). 

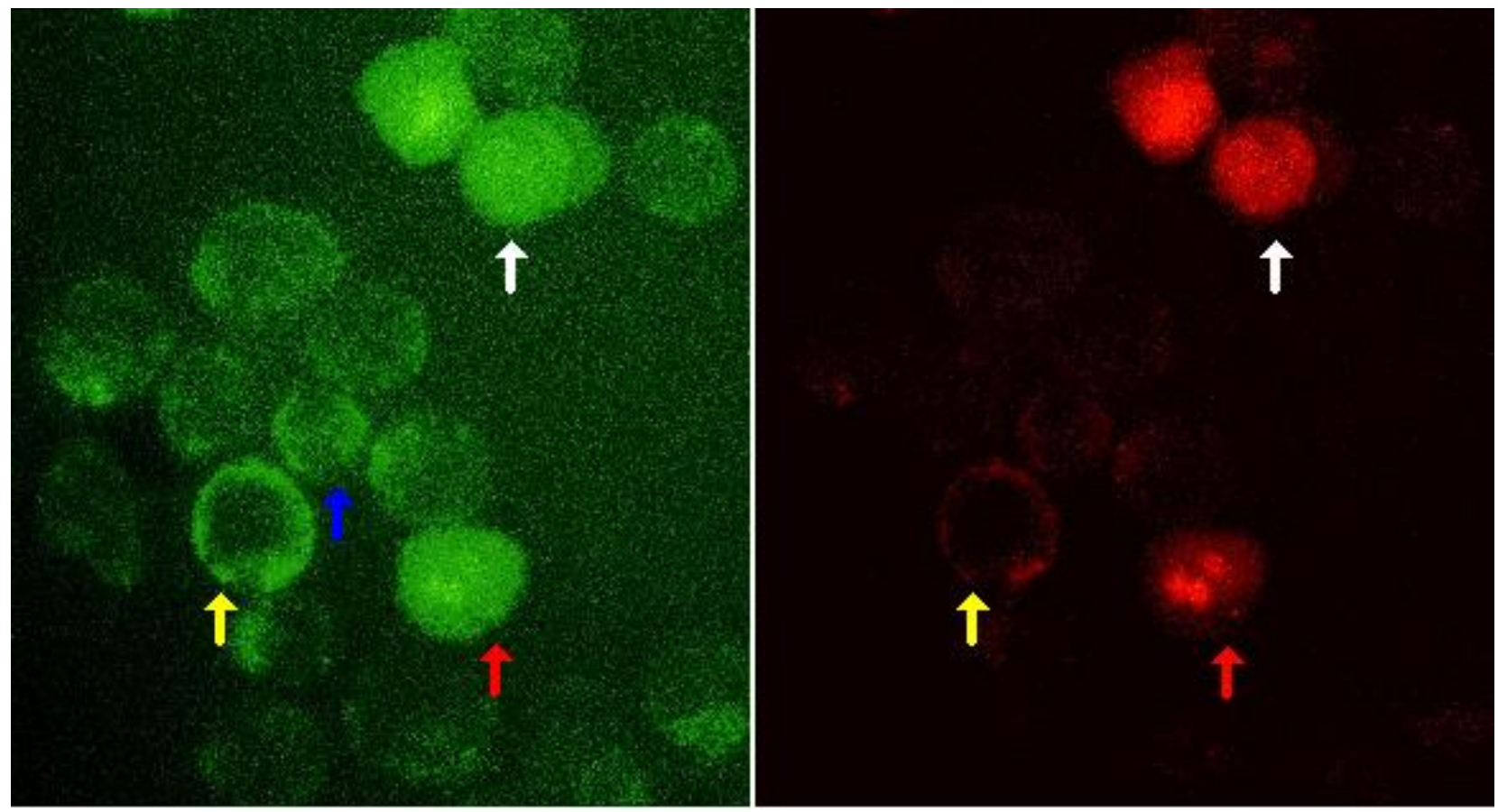

Fig. (3). Microphotography of HeLa cells undergoing apoptosis stained by FITC-Dextran and PI (x1000). HeLa cells were incubated at $43,5^{\circ} \mathrm{C}$ for 1 hour and at $37^{\circ} \mathrm{C}$ for 8 hours then labeled with FITC-Dextran and PI and analyzed by fluorescence microscopy. The left micrograph shows the green fluorescence (FITC), and the right micrograph shows the red fluorescence (PI). Because FITC-Dextran stained the early and late stages of apoptosis, the cells were labeled with FITC-Dextran more than PI. The white arrow shows apoptotic cells with plasma membrane rupture, the red arrow indicates the apoptotic cells with nucleus fragmentation, the yellow arrow shows apoptotic cells with nucleus alteration, and the blue arrow indicates apoptotic bodies. The living cells impermeable to FITC-Dextran aren't stained.

Table 2. FITC-Dextran or PI labelling of necrotic cells induced by a heat shock.

\begin{tabular}{|c|c|c|c|}
\hline \multirow{2}{*}{ Cells* } & \multicolumn{2}{|c|}{ \% stained cells } \\
\cline { 2 - 4 } & FITC-Dextran & PI & Statistics (Student t test) \\
\hline PBMC control & $1 \pm 0.42$ & $0.47 \pm 0.32$ & NS \\
\hline PBMC heated at $50^{\circ} \mathrm{C}$ & $41.7 \pm 11.2$ & $39.5 \pm 10.6$ & $\mathrm{p}<0.2$ \\
\hline PBMC heated at $60^{\circ} \mathrm{C}$ & $77 \pm 17$ & $70.3 \pm 11.6$ & \\
\hline
\end{tabular}

${ }^{*}$ Cells were heated to $50^{\circ} \mathrm{C}$ or $60^{\circ} \mathrm{C}$ for 1 hour and then stained with PI and FITC-Dextran, and analyzed by flow cytometry. Control cells were unheated. PBMC were obtained from healthy donors and results represent the means \pm S.D of 16 donors tested twice.

\section{DISCUSSION}

FITC-Dextran did not penetrate living cells, but during apoptosis or necrosis it was internalized and concentrated by binding to cellular proteins. In contrast to PI, FITC-Dextran was internalized in the majority of the heat shock stressed cells and therefore it could be used as a marker to identify cells in the early as well as in the late stages of apoptosis. PI marks apoptotic cells having a nucleus, binds and marks DNA, but it is unable to detect the different phases of apoptosis [13].

In early apoptosis, phosphatidylserine translocates from the inner leaflet of plasma membrane to the outer leaflet. This phenomenon can be detected in flow cytometry by the binding to the phosphatidylserine of the outer leaflet of FITC-conjugated Annexin V [14, 15]. Larger changes in the integrity of the plasma membrane has not been described [8]. Apoptotic cells in the early phase exclude viability testing dyes such as trypan blue or propidium iodide (PI). PI, penetrates in apoptotic cells at a late stage or in necrotic cells and stains the nucleus [16]. The integrity of the plasma membrane seem to contrast with the depolarization and the alteration of the permeability of the mitochondrial membrane with consequent release of proteins such as cytochrome c, which are early apoptotic events of the intrinsic pathway [10].

Different methods are used to assess cell death or mitochondrial dysfunction [17]: detection of activated enzymes such as caspases [18], alteration of the asymmetry of the membrane as the flip-flop of phosphatidylserine [8], DNA damage by staining with dyes as PI or Hoechst 33342 $[19,20]$. These markers can detect apoptosis, but they are not able to label a very late stage of apoptosis.

During the late stage of apoptosis, cell DNA is fragmented by endonucleases. The TUNEL technique 

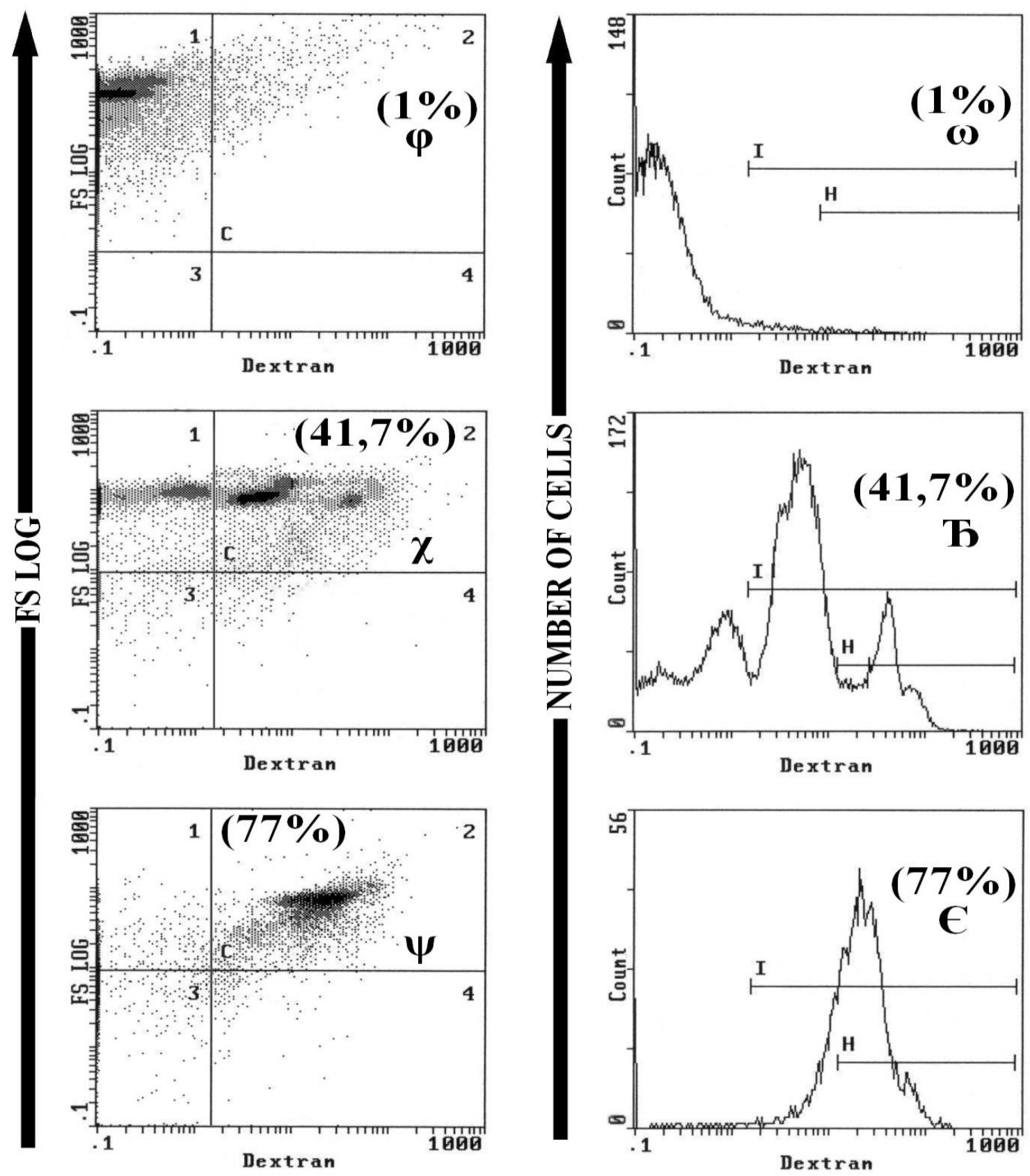

FITC

Fig. (4). Flow cytometric analysis of necrotic PBMC stained with FITC-Dextran. Healthy donors $\mathrm{PBMC}$ were heated at $50^{\circ} \mathrm{C}$ or $60^{\circ} \mathrm{C}$ for 1 hour, stained with FITC-Dextran and analyzed by flow cytometry. The numbers in parenthesis are the mean percentage observed with 16 healthy donors; each one tested two times.

The histograms at the top show the background staining observed with the live control cells (1\% dead cells targeted by the cursor I), histograms located in the middle show the cells heated at $50^{\circ} \mathrm{C}$, histograms at the bottom show the cells heated to $60^{\circ} \mathrm{C}$. The left histograms $(\varphi, \chi, \psi)$ are bi-parametric, log FS versus green fluorescence (FITC-Dextran). The right histograms $(\omega\rceil,, \epsilon)$, are mono-parametric and show the percentage of cells with various fluorescence intensity after staining with FITC-Dextran.

On the histogram $\mathrm{h}$ each peak corresponds to different stages of necrosis, on the histogram $\epsilon$ there is a single peak corresponding to dead cells.

(terminal uridine nucleotide end labeling) using TdT (terminal deoxynucleotidyl transferase), detects these DNA fragments by fixing dUTP (deoxyribonucleotide triphosphate) coupled to a label to the free $3^{\prime} \mathrm{OH}$ ends. TUNEL technique allows to detect apoptotic cells in late stage [21]. The commonly used tracers vary in molecular size and the chemical nature, the combination of techniques is required to track the various stages of apoptosis.

We tested FITC-Dextran to investigate alterations of plasma membrane permeability in apoptosis and necrosis. 
FITC-Dextran has the advantage of being stable, water soluble, non-toxic to cells and available in different molecular weight from 2000 to 15000 . The different experiments in this work were performed by Fluorescein Isothiocyanate Dextran MW 4000. Dextran is a polysaccharide consisting of linear chains of D-glucose linked by $\alpha$ (1-6) glycosidic bonds and branched by $\alpha$ (1-3) glycosidic linkages. It is generally extracted from the bacteria type Leuconostoc mesenteroide or streptococcus; it binds to proteins in the physiological $\mathrm{pH}$ and ionic strength [22]; it has no spontaneous fluorescence.

FITC-dextran was already used to study the permeability of membranes [23, 24]. It has been widely used to characterize the blood-brain barrier and to quantify the alteration of its permeability during ischemic stroke, trauma, infarction, inflammation and brain tumors. Studies on vascular permeability were performed using FITC-Dextran in deep tissues, intestine, kidney, brain oedemas, and peripheral nerves $[25,26]$. FITC-Dextran was also used to determine the mechanisms of the transport of molecules across vascular endothelial cells, and it has been suggested that the rate of transport through inter-cellular junctions depends on the molecular size of FITC-dextran [27]. FITCdextran, can not passively enter the cells, it penetrates through endocytosis. Thus it was used as a marker to study the encapsulation process and endocytosis of substances by erythrocytes [28, 29], the pinocytosis by leukocytes [30], and the vesicular $\mathrm{pH}$ in a variety of cell types including hepatocytes, kupffer cells and parenchymal cells [31, 32]. During trauma of the plasma membranes, FITC-Dextran diffuses through passages in the membrane of about 3-5 nm, causing intense staining of the cytoplasm. This phenomenon has been confirmed in a variety of cells including epidermal cells, intestinal cells and fibroblasts [33, 34]. Thus, FITCDextran was used as a molecular marker to measure the absorption of proteins in living cells by electroporation [35], to study its distribution in CHO cells by sonoporation [36], and to detect the permeability of the plasma membranes of dead cells [37].

Apoptosis can be induced by various techniques including hyperthermia. Indeed hyperthermia between $41.5^{\circ} \mathrm{C}$ to $46^{\circ} \mathrm{C}$ is widely used to kill cancer cells. However certain cancer cells such as prostate cells are necrotic at temperatures above $46^{\circ} \mathrm{C}$ [38]. By gradually increasing the temperature from $37^{\circ} \mathrm{C}$ to $46^{\circ} \mathrm{C}$ for 1 hour incubation, apoptosis was increased gradually to a maximum at $43^{\circ} \mathrm{C}$, but above $46^{\circ} \mathrm{C}$ cell death was due to necrosis [39-43]. It has been suggested that heat stress on intestinal epithelial cells IEC- 6 between $40^{\circ} \mathrm{C}$ and $43^{\circ} \mathrm{C}$ for $2-5$ hours produces $11.9 \%$ to $85 \%$ apoptotic cells against $3.6 \%$ in non heated controls [44]. These results are similar to our results obtained from HeLa cells hyperthermia at $43.5^{\circ} \mathrm{C}$ for 1 hour, followed by incubation at $37^{\circ} \mathrm{C}$ for 8 hours.

Many studies have been carried out on several types of cells to study the induction of apoptosis by hyperthermia. It appears that the induction and regulation mechanisms vary among different cell types. If activation of the mitochondrial pathway is usually accepted, however the results are conflicting on the initiator. With Jurkat T-lymphocytes an essential role for caspases was shown. The activation of initiator caspase 9 is essential in the execution of apoptosis induced by heat shock. Mitochondrial outer membrane permeability and cytochrome c release occur downstream of initial caspase 9 activation [45]. In contrast, it was observed that caspase 9 as well as other known initiator caspases, were not essential for the activation of the mitochondrial pathway. However activation requires a new apical protease with caspase-like activity [46]. Heat shock alters other physiological functions of these cells in reducing the splicing of pre-mRNA, U2AF35, SF3a3 and snRNP [47].

Thermal shock causes the denaturation and aggregation of cell proteins, but cells respond to hyperthermia by synthesizing molecular chaperones hsps (heat shock proteins) that protect against necrosis and apoptosis. Hsps bind to cell proteins exposed to stress and maintain their conformation [48]. It has been reported that thermal shock of PC12 cells induces the expression of apoptotic proteins such as JNK (c-Jun-N-terminale kinase), but the anti-apoptotic protein Hsp70 binds JNK to protect cells against heat stress [49]. A work mentioned that tobacco smoke induces cell apoptosis and necrosis, while the anti-apoptotic proteins Bcl2 and Hsp70 offset this induction by protecting cells against oxidative damage, lipid peroxidation and ROS (reactive oxygen species) [50]. Other studies have indicated that hyperthermia of testicles in cryptorchidism, varicocele or chronic fever induced the expression of p53 apoptotic protein. This protein is co-regulated by MTA1 (Metastasisassociated protein 1) which protects cells against heat stress [51]. In HeLa cells, which we have used in our work, it was shown that hyperthermia induces apoptosis by ROS production and through receptors such as FAS [52].

To determine whether the FITC-Dextran internalization by a cell is due to an alteration of the permeability of the membrane caused by heat only, we compared the internalization of FITC-Dextran at various temperatures. After induction of HeLa cells apoptosis by heating at $43.5^{\circ} \mathrm{C}$, the percentage $(79.6 \%)$ of cells stained by FITC-Dextran, was higher than those observed at $50^{\circ} \mathrm{C}(41.7 \%)$ and $60^{\circ} \mathrm{C}$ $(77 \%)$. It seems that the internalization of FITC-Dextran was more pronounced during apoptosis or by steps before apoptosis than the combined effect of heating and necrosis. In fact, after cells were subjected to a thermal stress at $43.5^{\circ} \mathrm{C}$ for 1 hour, they were incubated 8 hours at $37^{\circ} \mathrm{C}$ to induce apoptosis. During this incubation, the cells are also trying to repair the damage due to thermal shock and different processes will occur such as endocytosis of macromolecules (this is the case of polysaccharide) or overexpression of hsp that interacts with cell membranes to ensure homeostasis or cell survival $[53,54]$. Similarly, it has been shown that endocytosis is a reversible process occuring in the early phase of apoptosis [55]. At this stage FITCDextran may be internalized by endocytosis.

Once it has entered the cell, FITC-Dextran is concentrated by binding to cytoplasmic or nuclear molecules. After being subjected to fatal hyperthermia, apoptotic cells and necrotic cells had internalized FITCdextran proportionally to their damage. The percentage of apoptotic cells stained with FITC-Dextran was three times higher than those stained with PI. It remains to show, if apoptosis goes to completion in all the cells that internalize 
FITC-Dextran. Reversibility of apoptosis was observed in several cell types including HeLa cells. In the early phase of apoptosis, some cells can restore the exposure of phosphatidylserine on their membrane, repair mitochondrial damage or stop caspase activation [56, 57]. In the advanced stage of apoptosis corresponding to DNA damage, some cells can survive by becoming clonogenic $[58,59]$. Staining of cells with FITC-Dextran is useful in the study of apoptosis or necrosis by flow cytometry in various pathologies such as infectious diseases, cellular aging, cancer, lethal hyperthermia, inflammation and autoimmune diseases.

\section{ABBREVIATIONS}

\begin{tabular}{|c|c|}
\hline AP-HP & $=$ Assistance Publique des Hôpitaux de Paris \\
\hline $\mathrm{BP}$ & $=$ Band pass \\
\hline $\mathrm{CD}$ & $=$ Cluster of Differentiation \\
\hline DL & $=$ Dichroic Long-pass \\
\hline dUTP & $=$ deoxyribouridine Triphosphate \\
\hline FAS & $=$ TNF Receptor Superfamily, Member 6 \\
\hline FL & $=$ Fluorescent Light \\
\hline FITC-Dextran = & $\begin{aligned}= & \text { Fluorescein isothiocyanate coupled to } \\
\text { dextran } & \end{aligned}$ \\
\hline FS & $=$ Forward Scatter \\
\hline hsp & $=$ heat shock protein \\
\hline JNK & $=\mathrm{c}$-Jun-N-terminale kinase \\
\hline PBMC & $=$ Peripheral Blood Mononuclear Cells \\
\hline PI & $=$ Propidium iodide \\
\hline ROS & $=$ Reactive Oxygen Species \\
\hline SF3a3 & $=$ Splicing Factor $3 \mathrm{~A}$ subunit 3 \\
\hline SS & $=$ Side Scatter \\
\hline snRNP & $=$ small nuclear ribonucleoproteins \\
\hline $\mathrm{TdT}$ & $=$ Terminal deoxynucleotidyl Transferase \\
\hline TUNEL & $=$ Terminal Uridine Nucleotide End labeling \\
\hline $\mathrm{U} 2 \mathrm{AF} 35$ & $\begin{aligned}= & \text { Splicing factor U2AF U2 (small nuclear } \\
& \text { RNA auxiliary factor) } 35 \mathrm{kDa} \text { subunit }\end{aligned}$ \\
\hline htpR & $\begin{aligned}= & \text { heat shock regulatory gene - heat-shock } \\
& \text { promoters }\end{aligned}$ \\
\hline
\end{tabular}

\section{CONFLICT OF INTEREST}

The authors confirm that this article content has no conflict of interest.

\section{ACKNOWLEDGEMENTS}

We thank for critical discussions and review of the manuscript Sebastien Bardin, PhD and for assistance given to complete the work Marie-Hélène Maës, Annie-Claire Abuaf-Bardin, Lucienne Masse and Marie-Atoinette Ranguin AP-HP. This work was supported by Association Claude Bernard and Robert Debré.

\section{REFERENCES}

[1] Moodley K, Weiss SF. Downregulation of the non-integrin laminin receptor reduces cellular viability by inducing apoptosis in lung and cervical cancer cells. PLoS One 2013; 8: e57409.

[2] Ashida $\mathrm{H}$, Mimuro $\mathrm{H}$, Ogawa $\mathrm{M}$, et al. Cell death and infection: a double-edged sword for host and pathogen survival. J Cell Biol 2011; 195: 931-42.

[3] Majno G, Joris I. Apoptosis, oncosis, and necrosis. An overview of cell death. Am J Pathol 1995; 146: 3-15.

[4] Proskuryakov SY, Gabai VL, Konoplyannikov AG. Necrosis is an active and controlled form of programmed cell death. Biochemistry (Mosc) 2002; 67: 387-408.

[5] Vermes I, Haanen C, Reutelingsperger C. Flow cytometry of apoptotic cell death. J Immunol Methods 2000; 243: 167-90.

[6] Vermes I, Haanen C, Steffens-Nakken H, Reutelingsperger C. A novel assay for apoptosis. Flow cytometric detection of phosphatidylserine expression on early apoptotic cells using fluorescein labelled Annexin V. J Immunol Methods 1995; 184: 39-51.

[7] Hamel W, Dazin P, Israel MA. Adaptation of a simple flow cytometric assay to identify different stages during apoptosis. Cytometry 1996; 25: 173-81.

[8] Koopman G, Reutelingsperger CP, Kuijten GA, Keehnen RM, Pals ST, van Oers MH. Annexin V for flow cytometric detection of phosphatidylserine expression on B cells undergoing apoptosis. Blood 1994; 84: 1415-20.

[9] Vermes I, Haanen C, Richel DJ, Schaafsma MR, KalsbeekBatenburg E, Reutelingsperger CP. Apoptosis and secondary necrosis of lymphocytes in culture. Acta Haematol 1997; 98: 8-13.

[10] Jiang X, Wang X. Cytochrome C-mediated apoptosis. Annu Rev Biochem 2004; 73: 87-106.

[11] Sellins KS, Cohen JJ. Gene induction by gamma-irradiation leads to DNA fragmentation in lymphocytes. J Immunol 1987; 139: 3199-206.

[12] Spaulding C, Guo W, Effros RB. Resistance to apoptosis in human $\mathrm{CD} 8+\mathrm{T}$ cells that reach replicative senescence after multiple rounds of antigen-specific proliferation. Exp Gerontol 1999; 34: 633-44.

[13] Chen S, Cheng AC, Wang MS, Peng X. Detection of apoptosis induced by new type gosling viral enteritis virus in vitro through fluorescein annexin V-FITC/PI double labeling. World J Gastroenterol 2008; 14: 2174-8.

[14] van Engeland M, Nieland LJ, Ramaekers FC, Schutte B, Reutelingsperger CP. Annexin V-affinity assay: a review on an apoptosis detection system based on phosphatidylserine exposure. Cytometry 1998; 31: 1-9.

[15] Kain SR, Ma JT. Early detection of apoptosis with annexin Venhanced green fluorescent protein. Methods Enzymol 1999; 302: 38-43.

[16] Bacsó Z, Everson RB, Eliason JF. The DNA of annexin V-binding apoptotic cells is highly fragmented. Cancer Res 2000; 60: 4623-8. Vayssiere JL, Petit PX, Risler Y, Mignotte B. Commitment to apoptosis is associated with changes in mitochondrial biogenesis and activity in cell lines conditionally immortalized with simian virus 40. Proc Natl Acad Sci U S A 1994; 91: 11752-6.

[18] Durrieu F, Belloc F, Lacoste L, et al. Caspase activation is an early event in anthracycline-induced apoptosis and allows detection of apoptotic cells before they are ingested by phagocytes. Exp Cell Res 1998; 240: 165-75.

[19] Curnow SJ, Barad M, Brun-Roubereau N, Schmitt-Verhulst AM. Flow-cytometric analysis of apoptotic and nonapoptotic T-cell receptor-transgenic thymocytes following in vitro presentation of antigen. Cytometry 1994; 16: 41-8.

[20] Elstein KH, Zucker RM. Comparison of cellular and nuclear flow cytometric techniques for discriminating apoptotic subpopulations. Exp Cell Res 1994; 211: 322-31.

[21] Resendes AR, Majó N, Segalés J, et al. Apoptosis in normal lymphoid organs from healthy normal, conventional pigs at different ages detected by TUNEL and cleaved caspase-3 immunohistochemistry in paraffin-embedded tissues. Vet Immunol Immunopathol 2004; 99: 203-13.

[22] Blume KG, Hoffbauer RW, Busch D, Arnold H, Löhr GW. Purification and properties of pyruvate kinase in normal and in pyruvate kinase deficient human red blood cells. Biochim Biophys Acta 1971; 227: 364-72. 
[23] Thorball N. FITC-dextran tracers in microcirculatory and permeability studies using combined fluorescence stereo microscopy, fluorescence light microscopy and electron microscopy. Histochemistry 1981; 71: 209-33.

[24] Thorball N. The electron microscopy of fluorescent dextrans (FITC-dextrans) in thin sections of tissue. Experientia 1982; 38: 876-8.

[25] Hoffmann A, Bredno J, Wendland M, Derugin N, Ohara P, Wintermark M. High and Low Molecular Weight Fluorescein Isothiocyanate (FITC)-Dextrans to Assess Blood-Brain Barrier Disruption: Technical Considerations. Transl Stroke Res 2011; 2: 106-11.

[26] Hultström D, Malmgren L, Gilstring D, Olsson Y. FITC-Dextrans as tracers for macromolecular movements in the nervous system. A freeze-drying method for dextrans of various molecular sizes injected into normal animals. Acta Neuropathol 1983; 59: 53-62.

[27] Hashida R, Anamizu C, Yagyu-Mizuno Y, Ohkuma S, Takano T. Transcellular transport of fluorescein dextran through an arterial endothelial cell monolayer. Cell Struct Funct 1986; 11: 343-9.

[28] Droleskey RE, Andrews K, Chiarantini L, DeLoach JR. Use of fluorescent probes for describing the process of encapsulation by hypotonic dialysis. Adv Exp Med Biol 1992; 326: 73-80.

[29] Alvarez FJ, Herráez A, Tejedor MC. Fluorescence analysis of carrier rat and human erythrocytes loaded with FITC-dextran. Cytometry 1996; 24: 181-9.

[30] Oliver JM, Berlin RD, Davis BH. Use of horseradish peroxidase and fluorescent dextrans to study fluid pinocytosis in leukocytes. Methods Enzymol 1984; 108: 336-47.

[31] Schreiber R, Stoll B, Lang F, Häussinger D. Effects of anisoosmolarity and hydroperoxides on intracellular $\mathrm{pH}$ in isolated rat hepatocytes as assessed by (2',7')-bis(carboxyethyl)-5(6)carboxyfluorescein and fluorescein isothiocyanate-dextran fluorescence. Biochem J 1994; 303: 113-20.

[32] Schreiber R, Zhang F, Häussinger D. Regulation of vesicular $\mathrm{pH}$ in liver macrophages and parenchymal cells by ammonia and anisotonicity as assessed by fluorescein isothiocyanate-dextran fluorescence. Biochem J 1996; 315: 385-92.

[33] Lin YC, Ho CH, Grinnell F. Fibroblasts contracting collagen matrices form transient plasma membrane passages through which the cells take up fluorescein isothiocyanate-dextran and $\mathrm{Ca} 2+$. Mol Biol Cell 1997; 8: 59-71.

[34] McNeil PL, Ito S. Molecular traffic through plasma membrane disruptions of cells in vivo. J Cell Sci 1990; 96: 549-56.

[35] Graziadei L, Burfeind P, Bar-Sagi D. Introduction of unlabeled proteins into living cells by electroporation and isolation of viable protein-loaded cells using dextran-fluorescein isothiocyanate as a marker for protein uptake. Anal Biochem 1991; 194: 198-203.

[36] Khanna S, Hudson B, Pepper CJ, Amso NN, Coakley WT. Fluorescein isothiocynate-dextran uptake by chinese hamster ovary cells in a $1.5 \mathrm{MHz}$ ultrasonic standing wave in the presence of contrast agent. Ultrasound Med Biol 2006; 32: 289-95.

[37] Moumaris M, Abuaf N. Use of labeled dextran for in-vitro assessment of increased cell permeability, cell death and apoptosis. Brevet $n^{\circ} 00 / 09235$, National Institute of Industrial Property (INPI - France) 2002; 2811682: A3.

[38] Case JA, Tucker RD, Park JB. Defining the heating characteristics of ferromagnetic implants using calorimetry. J Biomed Mater Res 2000; 53: 791-8.

[39] Khar A, Kumari AL, Pardhasaradhi BV, Varalakshmi Ch, Rangaraj N. Heat stress induced apoptosis in BC-8 cells derived from AK-5 tumor involves downregulation of $\mathrm{Bcl}-2$ and generation of reactive oxygen species. Indian J Exp Biol 2006; 44: 802-8.

[40] Kerr JF, Winterford CM, Harmon BV. Apoptosis. Its significance in cancer and cancer therapy. Cancer 1994; 73: 2013-26.
[41] Harmon BV, Corder AM, Collins RJ, et al. Cell death induced in a murine mastocytoma by $42-47{ }^{\circ} \mathrm{C}$ heating in vitro: evidence that the form of death changes from apoptosis to necrosis above a critical heat load. Int J Radiat Biol 1990; 58: 845-58.

[42] Harmon BV, Takano YS, Winterford CM, Gobé GC. The role of apoptosis in the response of cells and tumours to mild hyperthermia. Int J Radiat Biol 1991; 59: 489-501.

[43] Dyson JE, Simmons DM, Daniel J, McLaughlin JM, Quirke P, Bird CC. Kinetic and physical studies of cell death induced by chemotherapeutic agents or hyperthermia. Cell Tissue Kinet 1986; 19: 311-24.

[44] Yu J, Yin P, Yin J, et al. Involvement of ERK1/2 signalling and growth-related molecules' expression in response to heat stressinduced damage in rat jejunum and IEC-6 cells. Int J Hyperthermia 2010; 26: 538-55.

[45] Shelton SN, Dillard CD, Robertson JD. Activation of caspase-9, but not caspase-2 or caspase-8, is essential for heat-induced apoptosis in Jurkat cells. J Biol Chem 2010; 285: 40525-33.

[46] Milleron RS, Bratton SB. Heat shock induces apoptosis independently of any known initiator caspase-activating complex. J Biol Chem 2006; 281: 16991-7000.

[47] Yuan X, Kuramitsu Y, Furumoto H, et al. Nuclear protein profiling of Jurkat cells during heat stress-induced apoptosis by 2-DE and MS/MS. Electrophoresis 2007; 28: 2018-26.

[48] Sõti C, Sreedhar AS, Csermely P. Apoptosis, necrosis and cellular senescence: chaperone occupancy as a potential switch. Aging Cell 2003; $2: 39-45$.

[49] Murai H, Hiragami F, Kawamura K, et al. Differential response of heat-shock-induced p38 MAPK and JNK activity in PC12 mutant and PC12 parental cells for differentiation and apoptosis. Acta Med Okayama 2010; 64: 55-62.

[50] Vayssier M, Banzet N, François D, Bellmann K, Polla BS. Tobacco smoke induces both apoptosis and necrosis in mammalian cells: differential effects of HSP70. Am J Physiol 1998; 275: L771-9.

[51] Li W, Wu ZQ, Zhao J, et al. Transient protection from heat-stress induced apoptotic stimulation by metastasis-associated protein 1 in pachytene spermatocytes. PLoS One 2011; 6: e26013.

[52] Bettaieb A, Averill-Bates DA. Thermotolerance induced at a fever temperature of $40{ }^{\circ} \mathrm{C}$ protects cells against hyperthermia-induced apoptosis mediated by death receptor signalling. Biochem Cell Biol 2008; 86: 521-38.

[53] O'Neill KL, Fairbairn DW, Smith MJ, Poe BS. Critical parameters influencing hyperthermia-induced apoptosis in human lymphoid cell lines. Apoptosis 1998; 3: 369-75.

[54] Vega VL, Charles W, De Maio A. A new feature of the stress response: increase in endocytosis mediated by Hsp70. Cell Stress Chaperones 2010; 15: 517-27.

[55] Pereira C, Bessa C, Saraiva L. Endocytosis inhibition during H2O2-induced apoptosis in yeast. FEMS Yeast Res 2012; 12: 75560.

[56] Hammill AK, Uhr JW, Scheuermann RH. Annexin V staining due to loss of membrane asymmetry can be reversible and precede commitment to apoptotic death. Exp Cell Res 1999; 251: 16-21.

[57] Tang HL, Tang HM, Mak KH, et al. Cell survival, DNA damage, and oncogenic transformation after a transient and reversible apoptotic response. Mol Biol Cell 2012; 23: 2240-52.

[58] Hendry JH, Potten CS. Intestinal cell radiosensitivity: a comparison for cell death assayed by apoptosis or by a loss of clonogenicity. Int J Radiat Biol Relat Stud Phys Chem Med 1982; 42: 621-8.

[59] Dunne AL, Price ME, Mothersill C, McKeown SR, Robson T, Hirst DG. Relationship between clonogenic radiosensitivity, radiation-induced apoptosis and DNA damage/repair in human colon cancer cells. Br J Cancer 2003; 89: 2277-83. 